\title{
Incidence and Predictors of Postoperative Kyphotic Deformity after Thoracic Spinal Cord Tumor Resection
}

Hideyuki, Arima, ${ }^{1}$ Tomohiko, Hasegawa, ${ }^{1}$ Yu, Yamato, ${ }^{1,2}$ Go, Yoshida, ${ }^{1}$ Tomohiro, Banno, ${ }^{1}$ Shin, Oe, ${ }^{1,2}$ Yuki, Mihara, ${ }^{1}$ Hiroki, Ushirozako, ${ }^{1}$ Tomohiro, Yamada, ${ }^{1}$ Koichiro, Ide, ${ }^{1}$ Yuh, Watanabe, ${ }^{1}$ Keiichi, Nakai, ${ }^{1}$ Kenta, Kurosu, ${ }^{1}$ Yukihiro, Matsuyama ${ }^{1}$

${ }^{1}$ Department of Orthopaedic Surgery, Hamamatsu University School of Medicine, Hamamatsucity, Shizuoka, Japan

${ }^{2}$ Division of Geriatric Musculoskeletal Health, Hamamatsu University School of Medicine, Hamamatsu-city, Shizuoka, Japan

Conflicts of Interest: HA, TH, GY, TB, YM, HU, TY, KI, YW, KN, KK, and YM have nothing to disclose. YY and SO received donated laboratory funding from Medtronic Sofamor Danek Inc. (Memphis, TN, USA), Japan Medical Dynamic Marketing Inc. (Tokyo, Japan), and Meitoku Medical Institute Jyuzen Memorial Hospital (Hamamatsu, Japan).

Acknowledgments:

This study was reviewed and approved by the Hamamatsu University School of Medicine Institutional Review Board (IRB No. 20-112). We would like to thank Ms. Nao Kuwahara, Ms. Tomoe Mabuchi, Mr. Taku Nagao and Mr. Tomokazu Suzuki, Secretaries of the Department of Orthopedic Surgery, for their excellent technical assistance during data collection. We would also like to thank Editage for English language editing.

\section{Author Contributions}

Conception and design: Arima, Matsuyama.

Acquisition of data: Arima, Hasegawa, Yamato, Yoshida, Banno, Oe, Mihara, Ushirozako, Yamada, Ide, Watanabe, Nakai, Kurosu, Matsuyama.

Analysis and interpretation of data: Arima, Hasegawa, Matsuyama.

Drafting the article: Arima.

Critically revising the article: Arima, Banno, Oe, Ushirozako, Watanabe.

Reviewed submitted version of manuscript: Arima, Hasegawa, Yamato, Yoshida, Banno, Oe, Mihara, Ushirozako, Yamada, Ide, Watanabe, Nakai, Kurosu, Matsuyama.

Approved the final version of the manuscript on behalf of all authors: Arima.

Statistical analysis: Arima

Study supervision: Hasegawa, Matsuyama,

Corresponding author:

Hideyuki Arima M.D., Ph.D., ORCID 0000-0003-0586-6818

Department of Orthopedic Surgery, Hamamatsu University School of Medicine Japan, 
1-20-1, Handayama, Higashi-ku, Hamamatsu-city, Shizuoka, JAPAN 431-3192

Tel: $(+81)-53-435-2299$

Fax: (+81)-53-435-2296

E-mail: arihidee@gmail.com 
1 Incidence and Predictors of Postoperative Kyphotic Deformity after Thoracic Spinal Cord 2 Tumor Resection

3 
$\underline{\text { Structured abstract }}$

Introduction: Kyphotic deformity is common after spinal tumor resection surgery. An adequate field of view is needed to resect the spinal cord tumor, and, in some cases, the facet joint must be removed during laminectomy, and fixation may be performed simultaneously. In this study, we investigated the incidence of postoperative deformity after spinal tumor resection and the factors associated with postoperative deformity.

Methods: We retrospectively analyzed patients who underwent thoracic spinal cord tumor resection at a single institution between 2010 and 2017 and were followed up for at least 24 months after surgery. Fifty percent or more of the facet joint was removed during the laminectomy, and fixation was performed simultaneously. Patients were divided into two groups, with and without kyphotic deformity. Patient demographic characteristics (age at surgery and gender), whether they underwent primary surgery or reoperation, tumor level, pathological type, and surgical method were compared. Multiple linear regression analysis was performed to 15 identify independent predictors of kyphotic deformity.

Results: Thirty-one patients were found to be eligible. Thirteen patients had intramedullary spinal cord tumors. Laminectomy was performed in $52 \%(\mathrm{~N}=16)$, laminoplasty in $6 \%(\mathrm{~N}=2)$, and laminectomy and/or laminoplasty combined with fusion in $42 \%(\mathrm{~N}=13)$ of the patients.

20 During a mean follow-up period of 66.8 months, 12 (39\%) patients had postoperative kyphosis deformities, of which one patient (3\%, a 12-year-old girl who underwent combined postoperative radiation therapy) underwent kyphosis correction surgery three years after surgery. The number of laminectomies was independently associated with kyphotic deformity.

Conclusions: Although kyphotic deformity after spinal tumor surgery was observed in about $39 \%$ of the patients, corrective surgery was rarely required due to the progression of the deformity. The high number of laminectomies is a risk factor for postoperative kyphosis, and prophylactic fixation may be considered in cases of multiple laminectomies. 
Introduction:

Spinal cord tumors are tumors that develop in the spinal cord or its surrounding tissues ${ }^{1-5}$. Based on their location, spinal cord tumors can be divided into epidural spinal cord tumors, intradural extramedullary tumors, and intramedullary spinal cord tumors, which originate outside the dura mater, inside the dura mater and outside the spinal cord, and inside the spinal cord, respectively ${ }^{3,4}$. As the spinal cord tumor grows, it compresses the surrounding nerve tissue, resulting in sensory disturbances, pain, and movement disorders. Spinal cord tumors do not respond well to chemo- or radiation therapy and require surgical resection ${ }^{5}$. Although surgical resection is generally performed by a posterior approach, the development of kyphotic deformity has been reported after resection ${ }^{6-10}$. Resection of the posterior elements of the spine during tumor resection causes biomechanical instability ${ }^{11}$. Therefore, depending on the localization of the tumor, laminoplasty is performed instead of laminectomy ${ }^{9,12}$, and fusion is used simultaneously to prevent kyphosis after surgery in some cases ${ }^{13,14}$. Although kyphotic deformities after cervical spinal cord tumors are common ${ }^{8,15-17}$, there are not many reports of postoperative kyphotic deformities in thoracic spinal cord tumors ${ }^{10,14}$. In this study, we investigated the incidence of postoperative deformity after spinal tumor resection and the factors associated with postoperative deformity.

\section{Materials and methods:}

\section{Patient population}

This study was reviewed and approved by the Institutional Review Board of the authors' affiliated institution and adhered to the principles of the Declaration of Helsinki. We obtained written informed consent from all participants to publish our findings. We retrospectively analyzed patients who underwent thoracic spinal cord tumor resection at a single institution between 2010 and 2017 and were followed up for at least 24 months after surgery. Patients who underwent the anterior approach for spinal cord tumor resection were excluded.

Data on the following characteristics were extracted: age, gender, whether the surgery was a primary surgery or a reoperation, tumor level, and histopathological type of the tumor. Regarding surgical data, surgical techniques (laminectomy only, laminoplasty only, combined laminectomy and laminoplasty, and laminectomy and/or laminoplasty combined with fusion) and the number of laminoplasties or laminectomies performed were investigated.

\section{Surgical techniques}

All patients underwent surgical resection under general anesthesia, and intraoperative spinal cord monitoring was performed. The patient was in a prone position, and surgery was performed using a posterior median approach. The lamina was exposed, and laminectomy or laminoplasty was performed using a high-speed bur. Concerning laminoplasty, French-door laminoplasty was performed using the method described by Kurokawa with some modifications for patients with tumors in the cervicothoracic region ${ }^{18}$. Recapping laminoplasty was performed using a T-saw for tumors in the thoracic or thoracolumbar spine, according to the method described by Kawahara ${ }^{19}$. In the case of extradural tumors, the facet joints were resected, if necessary. After confirming the localization of the tumor by intraoperative ultrasound for lesions within the spinal canal, total resection was performed under the microscope as much as possible. For lesions 
outside the intervertebral foramen, enucleation was performed under the membrane using a microscope. For intradural extramedullary tumors, the dura was incised under the microscope, and the arachnoid membrane was sharply dissected to expose the tumor. The cephalic and caudal sides of the tumor were identified. If the tumor originated from the dura, the entire dura was resected, and if the tumor originated from a nerve root, the nerve root entering the tumor was cut, and the tumor was removed. In intramedullary tumors, a median myelotomy was performed by using a diamond knife to dissect or resect the tumor sharply. The surface of the tumor should be carefully coagulated using bipolar coagulation to harden the tumor coat. The tip of the bipolar coagulator may cause the vessel wall of the tumor to break, causing heavy bleeding. Therefore, the side of the bipolar coagulator was used to cauterize the tumor, and the hardened coating was gradually peeled off from the normal spinal cord with a spatula. After resection, the presence of residual tumors was confirmed by intraoperative ultrasonography. An adequate field of view was needed to resect the spinal cord tumor, and, in some cases, $50 \%$ or more of the facet joint was removed during the laminectomy, and fixation was performed simultaneously.

\section{Magnetic resonance imaging measurements}

The kyphotic angle between the cephalic endplate of the most upper vertebral body and the caudal endplate of the most lower vertebral body that underwent laminectomy or laminoplasty was measured on magnetic resonance imaging (MRI) before surgery and at the last follow-up (measured as upper vertebra [UV]-lower vertebra [LV] kyphotic angle) (Figure 1). The $\Delta \mathrm{UV}-\mathrm{LV}$ kyphotic angle was calculated by subtracting the UV-LV kyphotic angle at baseline from the UV-LV angle at the last follow-up, and an increase of more than $10^{\circ}$ was defined as postoperative kyphosis. Based on the presence or absence of the kyphotic deformity, patients were divided into two groups as follows: postoperative kyphosis and no postoperative kyphosis groups. Characteristics such as patient demographics (age at surgery and gender), primary surgery or reoperation, tumor level, pathological type, and surgical method were compared.

\section{Statistical analyses}

All values are expressed as mean \pm standard deviation. The Shapiro-Wilk test was used to verify the assumption regarding the normal distribution of the data. The paired sample t-test or the Wilcoxon signed-rank test was used for within-group comparisons of continuous variables. Differences between the groups were evaluated using the unpaired two-sample t-test or the Mann-Whitney test. The chi-square test or Fisher's exact test was used to test for significant differences in categorical variables between the groups. Multiple linear regression analyses were used to determine the relationship between $\Delta$ UV-LV kyphotic angle and explanatory variables. The $\Delta$ UV-LV kyphotic angle was used as an objective, continuous variable, and age at surgery, UV-LV kyphotic angle at baseline, number of laminectomies, and presence or absence of fixation were used as explanatory variables. In the group of patients who did not undergo prophylactic fixation, the number of laminectomies was dichotomized according to the optimal cut-off value obtained by receiver-operating-characteristic (ROC) curve analysis, and a ROC curve was constructed. The optimal cut-off value for ROC corresponds to the point of an optimal trade-off between sensitivity and specificity. The ROC curve was derived from the cut-off value of the number of laminectomies, with equal weights for both sensitivity and specificity, to distinguish between patients with "postoperative kyphosis" and "no postoperative kyphosis." 
The accuracy of the ROC curve was evaluated using the calculated area under the curve (AUC). A P-value of $<0.05$ was considered significant. Statistical analyses were performed using the Statistical Package for Social Sciences (SPSS) software (version 26.0; SPSS, Chicago, IL, USA).

$\underline{\text { Results: }}$

\section{Participant characteristics}

During the study period, 56 patients underwent thoracic spinal tumor resection, and 31 were available for follow-up more than 24 months after surgery. The cervicothoracic, thoracic, and thoracolumbar spinal tumor levels were seen in 1, 20, and 10 cases, respectively. There were 26 cases of intradural tumors, of which 13 were intramedullary. Twenty-six patients underwent primary surgeries, and five had undergone surgeries previously at other hospitals (Table 1). The histological diagnoses of the tumors were schwannoma, meningioma, ependymoma, hemangioma, myxopapillary ependymoma, hemangioblastoma, and others in $6,5,5,5,2,2$, and 6 cases, respectively (Table 1 ).

\section{Surgical details}

Sixteen patients underwent laminectomy only, one laminoplasty only, one combined laminectomy and laminoplasty, and 13 underwent laminectomy and/or laminoplasty combined with fusion (Table 2). The average numbers of laminectomies and laminoplasties were $3.1 \pm 1.8$ and $0.3 \pm 1.0$, respectively. The average number of vertebrae included in the laminectomy or laminoplasty was $3.3 \pm 1.7$.

\section{MRI measurements}

The UV-LV kyphotic angle ranged from $10.4^{\circ} \pm 10.9^{\circ}$ at baseline to $18.3^{\circ} \pm 14.6^{\circ}$ at the final follow-up with a $\Delta U V$-LV kyphotic angle of $7.9^{\circ} \pm 7.5^{\circ}$ (Table 3). There were 12 cases (39\%) of postoperative kyphosis with a $\Delta \mathrm{UV}$-LV kyphotic angle of $10^{\circ}$ or more. There was no significant difference in the UV-LV kyphotic angle at baseline between the two groups (postoperative kyphosis vs. no postoperative kyphosis: $14.3^{\circ} \pm 15.5^{\circ}$ vs. $\left.7.9^{\circ} \pm 5.9^{\circ}, \mathrm{P}=0.116\right)$.

\section{Differences in patient background, tumor level, and histology between the postoperative kyphosis and no postoperative kyphosis groups}

There was no significant difference in the follow-up time between the postoperative kyphosis and no postoperative kyphosis groups ( $78.8 \pm 31.9$ vs. $59.2 \pm 20.8$ months, $\mathrm{P}=0.077$; Table 1$)$. In addition, there was no significant association between the groups in terms of age, sex, whether the patient was reoperated or not, tumor level, tumor localization, tumor pathology, and postoperative kyphosis.

\section{Differences in surgical factors between the postoperative kyphosis and no postoperative kyphosis} groups

The number of laminectomies was significantly higher in the postoperative kyphosis group than in the no postoperative kyphosis group ( $3.9 \pm 2.2$ vs. $2.6 \pm 1.2$ vertebrae, $\mathrm{P}=0.046$; Table 2$)$. In patients without fixation $(\mathrm{n}=18)$, the number of laminectomies was significantly higher in the 44 postoperative kyphosis group than in the no postoperative kyphosis group ( $4.3 \pm 2.3$ vs. $2.4 \pm 0.7$ 
vertebrae, $\mathrm{P}=0.041)$. There was no significant difference in the number of laminoplasties between the two groups $(0.3 \pm 0.9$ vs. $0.3 \pm 1.1$ vertebrae, $\mathrm{P}=0.973)$ as well as in the total number of laminectomies or laminoplasties performed between the groups ( $4.0 \pm 1.9 \mathrm{vs.} 2.9 \pm$ 1.4 vertebrae, $\mathrm{P}=0.070$ ). No significant association was observed for radiation therapy between the postoperative kyphosis group and the no postoperative kyphosis group.

\section{Factors associated with postoperative kyphosis}

Spearman correlation analysis showed that $\Delta U V-L V$ kyphotic angle significantly correlated with number of laminectomies $(\mathrm{r}=0.550, \mathrm{P}=0.001)$ and number of vertebrae included in the laminectomy or laminoplasty $(\mathrm{r}=0.453, \mathrm{P}=0.011$; Table 4$)$. Multivariate analysis showed that number of laminectomies was independently associated with $\Delta U V$-LV kyphotic angle (standardization coefficient, 0.513; $\mathrm{P}=0.011$ ).

\section{Additional posterior fixation}

One (3\%) patient required delayed posterior fixation due to kyphosis. A 12-year-old girl with Ewing's sarcoma underwent a T7-T10 laminectomy with gross tumor resection. After tumor removal, she received radiation and chemotherapy. The T7-T10 kyphotic angle was $16^{\circ}$ preoperatively, but there was a gradual progression of kyphotic deformity postoperatively with an increase in the kyphotic angle to $29^{\circ}$ at three years postoperatively (Figure 2). T3-L3 corrective fixation surgery for increasing kyphotic deformity with back pain was performed three years after initial tumor resection.

\section{Differences in demographic and MRI parameters between patients with and without fixation}

There were no significant differences between patients with and without fixation in terms of age, sex, whether the patient was reoperated or not, tumor level, tumor pathology, or UV-LV kyphotic angle at baseline (Table 5). With regard to tumor localization, the ratio of patients with fixation among intradural intramedullary, intradural extramedullary, and extradural spinal cord tumors was significantly different $(\mathrm{P}=0.024)$. In the 18 patients without fixation, the ROC curve analysis indicated that the best cut-off level of the number of laminectomies for predicting the postoperative kyphosis was 3.5 , with a sensitivity and a specificity of $66.7 \%$ and $100 \%$, respectively. The AUC was 0.827 ( $\mathrm{P}=0.004 ; 95 \%$ confidence interval [CI], 0.607-1.047).

\section{Discussion:}

The purpose of this study was to evaluate the incidence of postoperative kyphotic deformity after resection of thoracic spinal cord tumors and whether corrective fixation was performed during follow-up for the kyphotic deformity. The study encompassed intradural and extradural thoracic spinal cord tumors, including intramedullary tumors, and investigated if tumor characteristics, site of origin, or surgical factors were associated with the postoperative kyphotic deformity. The results showed that $39 \%$ of the patients with thoracic spinal cord tumors had a postoperative kyphotic deformity within a mean follow-up period of about five years. However, patients requiring corrective fixation surgery for kyphotic deformity were few, with only one $(3 \%)$ such patient present in this study. Although there are many reports on kyphotic deformity after 44 cervical spinal cord tumor surgery $8,9,15,17,20,21$, there are not many reports on kyphotic deformity 45 after thoracic spinal cord tumor surgery ${ }^{10,21}$. Previous literature has reported that $2.4-27 \%$ of 
patients underwent additional fixation for postoperative kyphotic deformity during the postoperative course after cervical spinal cord tumor resection ${ }^{8,9,15,17,20,21}$. Regarding thoracic spinal cord tumors, Yeh et al. reported that the additional fixation was performed for postoperative kyphotic deformity in $5(33 \%)$ of 15 patients $^{21}$. Compared to these reports, the rate of additional fixation surgery in our study was very low. The risk factors for kyphotic deformity after spinal cord tumor resection requiring additional unscheduled fixation during follow-up have been reported to be the preoperative presence of spinal deformity ${ }^{16,17}$, surgery of three or more levels of laminectomy ${ }^{8}$, and more than $50 \%$ facetectomy ${ }^{17,22}$. Here, $13(42 \%)$ patients underwent prophylactic fixation at the time of simultaneous spinal tumor resection. Patients with and without intraoperative prophylactic fixation did not differ in age, tumor height, tumor pathology, or preoperative kyphotic angle. We used prophylactic fusion to prevent postoperative kyphosis deformity in patients who had more than $50 \%$ of the facet joint removed during the laminectomy, which may be related to the results of the low incidence of additional unscheduled fixation for postoperative kyphotic deformity. Prophylactic fixation was more frequent in epidural and intradural extramedullary tumors than in intradural intramedullary tumors. The reason for this may be that the dumbbell-type epidural tumors and meningiomas of intradural extramedullary tumors require partial or complete removal of facet joints during a laminectomy in some cases.

The average kyphotic angle between vertebrae in patients who underwent laminectomy or laminoplasty increased by $7.9^{\circ}$ postoperatively. Kobayashi et al. reported that the kyphotic deformity of the upper thoracic spine progressed by about $20^{\circ}$ after surgery for upper thoracic spinal cord tumors, but kyphosis did not progress in middle or lower thoracic spinal cord tumors ${ }^{10}$. The cervicothoracic spine, which is the transition between the flexible lordotic cervical spine and the relatively rigid kyphotic thoracic spine, can be mechanically vulnerable after laminectomy ${ }^{23}$. In our study, there was no significant difference in the incidence of kyphotic deformity after tumor resection among cervical thoracic, thoracic, and thoracolumbar spinal cord tumors. However, due to the small number of cervicothoracic cases in this study, further investigation is needed.

Regarding tumor localization, whether the spinal tumor was intradural or intramedullary was not associated with kyphotic deformity. Some cases of extradural tumors included those in which the tumor had penetrated the intervertebral foramen, and the facet joint had to be removed prior to tumor resection. These cases are a risk factor for postoperative kyphotic deformity ${ }^{16,22,24}$. In the present study, cases with facetectomy were treated with fusion.

The average number of laminectomies was 3.1 in this study, and the increased number of laminectomies was associated with postoperative kyphosis. Conversely, the number of laminoplasties averaged 0.3 and was not associated with postoperative kyphosis deformity. In the literature, there is no clear evidence that laminoplasty reduces the risk of postoperative kyphosis compared to laminectomy $y^{9,15,25}$. However, the importance of preserving the posterior supportive tissue has been suggested ${ }^{15}$. Our policy is to perform laminectomy or laminoplasty for spinal cord tumors as we believe that a sufficient margin of normal tissue above and below the tumor is necessary to prevent paralysis during tumor resection. Therefore, the number of laminectomies or laminoplasties (mean $=3.3$ levels) was not less than the mean of 2.6 levels reported by Sciubba et al. and 2.4 levels reported by Tatter et $\mathrm{al}^{8,15}$. The results of the ROC analysis showed 
that the cut-off value for the number of laminectomies to predict postoperative kyphosis progression was 3.5. This means that prophylactic fixation may be considered when performing a laminectomy of four or more vertebrae.

Spinal deformity after radiation therapy has been reported previously ${ }^{26-28}$. The effects of radiation are especially significant in immature spines ${ }^{28}$. In the present study, the kyphotic deformity was developed postoperatively and required additional fixation in a pediatric patient who underwent concomitant radiation therapy. Due to the limited number of patients who received radiation therapy in this study, the relationship between radiation therapy and kyphosis deformity possibly did not reach statistical significance. In pediatric patients with spinal cord tumors who undergo postoperative radiation therapy, patients and their families should be fully informed that kyphosis deformity may progress after surgery and require additional fixation surgery.

There are several limitations to this study. First, the study did not evaluate pre- and postoperative deformities on standing posteroanterior and lateral whole spine radiographs. The changes were based on local MRI findings, which may underestimate the progression of the kyphotic deformity. Since many patients did not have standing whole spine radiographs preoperatively and at final follow-up, we used MRI to assess kyphosis angle in this study. Second, in cases where tumor resection was combined with fixation, there may be a difference in alignment between the preoperative and immediate postoperative periods. Although there were cases in which the UV-LV angle increased postoperatively, even in cases in which fixation was combined, the change in the fixation angle at the time of surgery was not considered because MRI evaluated it before surgery and at the final follow-up. There were no cases with obvious screw loosening in the fixation group. Therefore, we speculate that the cases with increased UVLV kyphotic angle at the final follow-up despite combined fixation may have been kyphotic after intraoperative laminectomy and fixed in that alignment. Third, due to the retrospective nature of the study, clinical outcomes and neurological severity preoperatively and at the final follow-up were not assessed in some cases. Therefore, we could not analyze whether clinical outcomes and neurological severity were related to postoperative kyphotic deformity. In conclusion, although kyphotic deformity after spinal tumor surgery was observed in about $39 \%$ of the cases in the present study, corrective surgery was rarely required due to the progression of the deformity. We used prophylactic fusion to prevent postoperative kyphotic deformity in patients who had more than $50 \%$ of the facet joint removed during the laminectomy, which may be related to the low incidence of additional unscheduled fixation for postoperative kyphotic deformity. The high number of laminectomies is a risk factor for postoperative kyphosis, and prophylactic fixation may be considered in cases of multiple laminectomies. 


\section{REFERENCES}

2 1. Hirano K, Imagama S, Sato K, et al. Primary spinal cord tumors: review of 678

3 surgically treated patients in Japan. A multicenter study. Eur Spine J. 2012;21(10): 2019-26.

42 2. Engelhard HH, Villano JL, Porter KR, et al. Clinical presentation, histology, and

5 treatment in 430 patients with primary tumors of the spinal cord, spinal meninges, or cauda

6 equina. J Neurosurg Spine. 2010;13(1): 67-77.

3. Harrop JS, Ganju A, Groff M, et al. Primary intramedullary tumors of the spinal cord. Spine (Phila Pa 1976). 2009;34(22 Suppl): S69-77.

4. Zadnik PL, Gokaslan ZL, Burger PC, et al. Spinal cord tumours: advances in genetics and their implications for treatment. Nat Rev Neurol. 2013;9(5): 257-66.

5. Abd-El-Barr MM, Huang KT, Moses ZB, et al. Recent advances in intradural spinal tumors. Neuro Oncol. 2018;20(6): 729-42.

6. Shi W, Wang S, Zhang H, et al. Risk factor analysis of progressive spinal deformity after resection of intramedullary spinal cord tumors in patients who underwent laminoplasty: a report of 105 consecutive cases. J Neurosurg Spine. 2019;30(5): 655-63.

7. Ahmed R, Menezes AH, Awe OO, et al. Long-term incidence and risk factors for development of spinal deformity following resection of pediatric intramedullary spinal cord tumors. J Neurosurg Pediatr. 2014;13(6): 613-21.

8. Sciubba DM, Chaichana KL, Woodworth GF, et al. Factors associated with cervical instability requiring fusion after cervical laminectomy for intradural tumor resection. $\mathrm{J}$ Neurosurg Spine. 2008;8(5): 413-9.

9. Nori S, Iwanami A, Yasuda A, et al. Risk factor analysis of kyphotic malalignment after cervical intramedullary tumor resection in adults. J Neurosurg Spine. 2017;27(5): 518-27. 10. Kobayashi Y, Kawabata S, Nishiyama Y, et al. Changes in sagittal alignment after surgical excision of thoracic spinal cord tumors in adults. Spinal Cord. 2019;57(5): 380-7. 11. Lonstein JE. Post-laminectomy kyphosis. Clin Orthop Relat Res. 1977;128: 93-100. 12. Kobayashi K, Imagama S, Ando K, et al. Efficacy of conical laminoplasty after thoracic laminectomy. Clin Spine Surg. 2018;31(4): 156-61.

13. Anakwenze OA, Auerbach JD, Buck DW, et al. The role of concurrent fusion to prevent spinal deformity after intramedullary spinal cord tumor excision in children. J Pediatr Orthop. 2011;31(5): 475-9.

14. Hersh DS, Iyer RR, Garzon-Muvdi T, et al. Instrumented fusion for spinal deformity after laminectomy or laminoplasty for resection of intramedullary spinal cord tumors in pediatric patients. Neurosurg Focus. 2017;43(4): E12.

15. Tatter C, Fletcher-Sandersjöö A, Persson O, et al. Incidence and predictors of kyphotic deformity following resection of cervical intradural tumors in adults: a population-based cohort study. Acta Neurochir (Wien). 2020;162(11): 2905-13.

16. Fassett DR, Clark R, Brockmeyer DL, et al. Cervical spine deformity associated with resection of spinal cord tumors. Neurosurg Focus. 2006;20(2): E2.

40 17. Katsumi Y, Honma T, Nakamura T. Analysis of cervical instability resulting from 41 laminectomies for removal of spinal cord tumor. Spine (Phila Pa 1976). 1989;14(11): 1171-6.

$42 \quad$ 18. Kurokawa T. [Double door laminoplasty by longitudinal splitting of the spinous 43 process]. Bessatsu Seikeigeka. 1982;2: 234-40 Japanese.

44 19. Kawahara N, Tomita K, Shinya Y, et al. Recapping T-saw laminoplasty for spinal cord 45 tumors. Spine (Phila Pa 1976). 1999;24(13): 1363-70. 
12 20. McGirt MJ, Chaichana KL, Atiba A, et al. Incidence of spinal deformity after resection

2 of intramedullary spinal cord tumors in children who underwent laminectomy compared with

3 laminoplasty. J Neurosurg Pediatr. 2008;1(1): 57-62.

4 21. Yeh JS, Sgouros S, Walsh AR, et al. Spinal sagittal malalignment following surgery

5 for primary intramedullary tumours in children. Pediatr Neurosurg. 2001;35(6): 318-24.

$622 . \quad$ Papagelopoulos PJ, Peterson HA, Ebersold MJ, et al. Spinal column deformity and

7 instability after lumbar or thoracolumbar laminectomy for intraspinal tumors in children and

8 young adults. Spine (Phila Pa 1976). 1997;22(4): 442-51.

9 23. An HS, Vaccaro A, Cotler JM, et al. Spinal disorders at the cervicothoracic junction.

10 Spine (Phila Pa 1976). 1994;19(22): 2557-64.

11 24. Avila MJ, Walter CM, Skoch J, et al. Fusion after intradural spine tumor resection in

12 adults: a review of evidence and practices. Clin Neurol Neurosurg. 2015;138(169-73.

13 25. McGirt MJ, Garcés-Ambrossi GL, Parker SL, et al. Short-term progressive spinal

14 deformity following laminoplasty versus laminectomy for resection of intradural spinal tumors:

15 analysis of 238 patients. Neurosurgery. 2010;66(5): 1005-12.

16 26. Riseborough EJ. Irradiation induced kyphosis. Clin Orthop Relat Res. 1977;128: 101-

176.

18 27. Katzman H, Waugh T, Berdon W. Skeletal changes following irradiation of childhood

19 tumors. J Bone Joint Surg Am. 1969;51(5): 825-42.

$2028 . \quad$ de Jonge T, Slullitel H, Dubousset J, et al. Late-onset spinal deformities in children

21 treated by laminectomy and radiation therapy for malignant tumours. Eur Spine J. 2005;14(8):

$22 \quad 765-71$.

23 
$1 \quad$ Figure legends

Figure 1. Upper vertebra (UV)-lower vertebra (LV) kyphotic angle. The kyphotic angle between 4 the cephalic endplate of the most UV and the caudal endplate of the most LV that underwent 5 laminectomy or laminoplasty is measured on magnetic resonance imaging.

Figure 2. Representative sagittal magnetic resonance images of a 12-year-old girl with Ewing's 8 sarcoma preoperatively (A) and three years postoperatively (B). She underwent a T7-T10

9 laminectomy with gross tumor resection. After tumor removal, she received radiation and 10 chemotherapy. The T7-T10 kyphotic angle was $16^{\circ}$ preoperatively, but there was a gradual 11 progression of kyphotic deformity postoperatively, with an increase in the kyphotic angle to $29^{\circ}$ 12 at three years postoperatively. T3-L3 fixation for increasing kyphotic deformity with back pain 13 was performed at three years after tumor resection surgery $(\mathrm{C})$. 


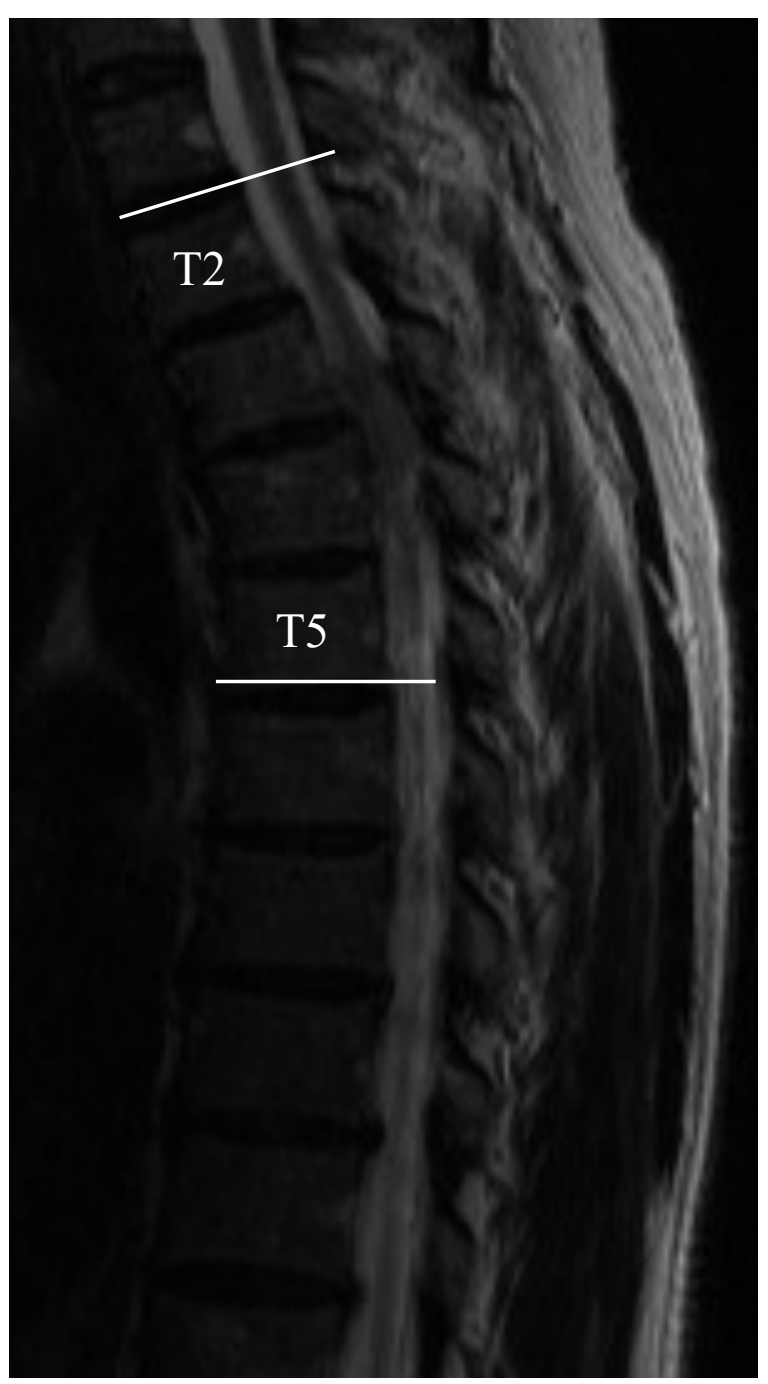


Spine Surgery and Related Research J-STAGE Advance Publication (August 23, 2021)

(C) The J apanese Society for Spine Surgery and Related Research. CC BY- NC- ND 4.0 (https://creativecommons.org/licenses/by- nc- nd/4.0/).

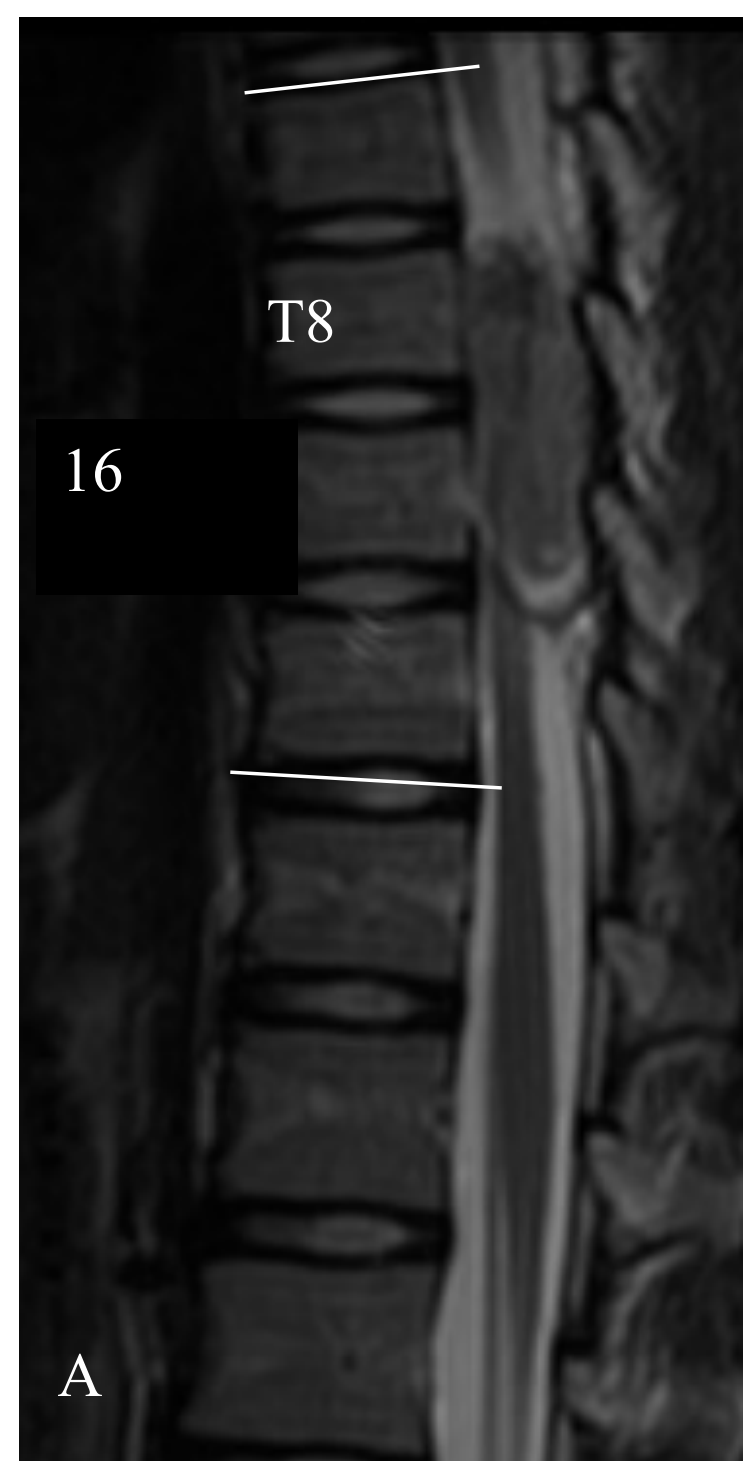


Spine Surgery and Related Research J-STAGE Advance Publication (August 23, 2021)

(C) The J apanese Society for Spine Surgery and Related Research. CC BY- NC- ND 4.0 (https://creativecommons.org/licenses/by- nc- nd/4.0/).

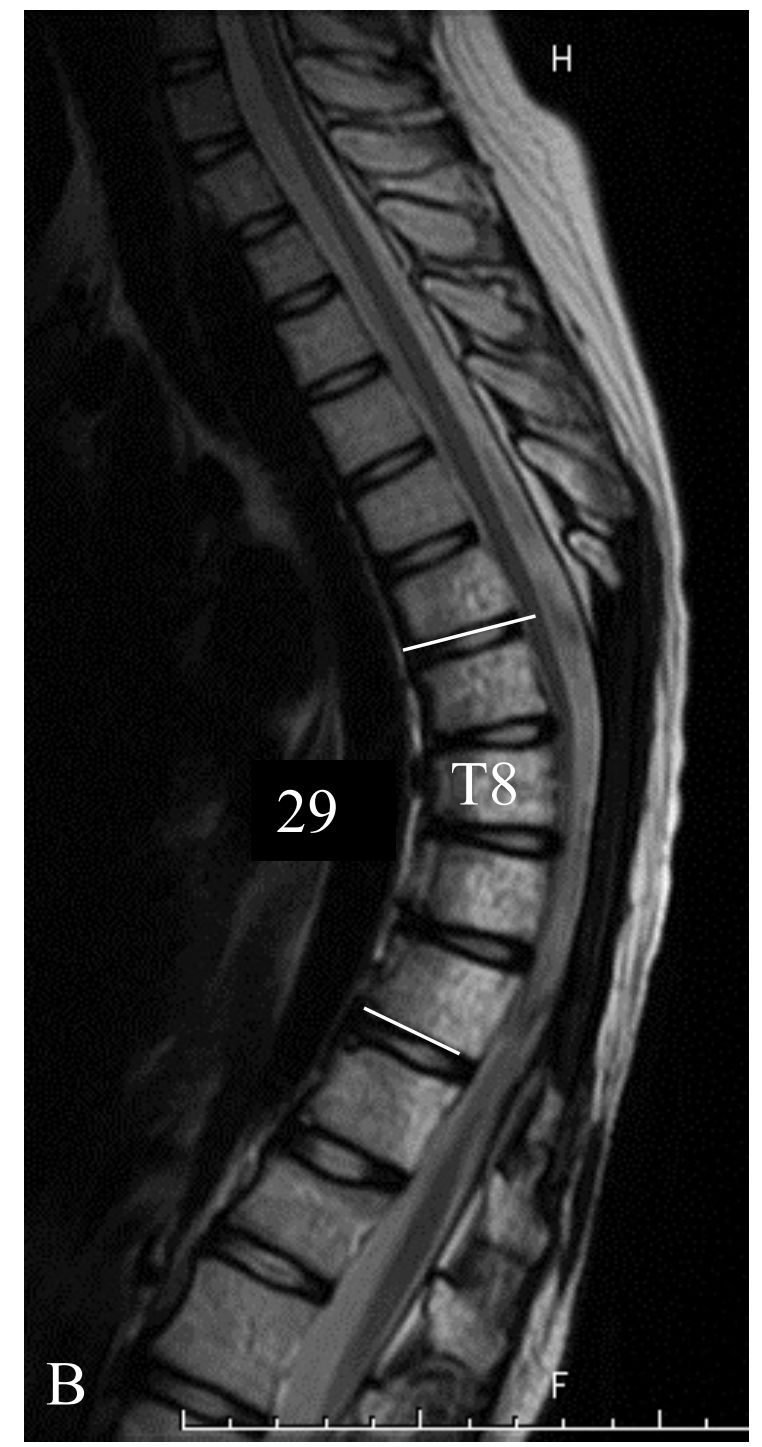


Spine Surgery and Related Research J-STAGE Advance Publication (August 23, 2021)

(C) The J apanese Society for Spine Surgery and Related Research. CC BY- NC- ND 4.0 (https://creativecommons.org/licenses/by- nc- nd/4.0/).

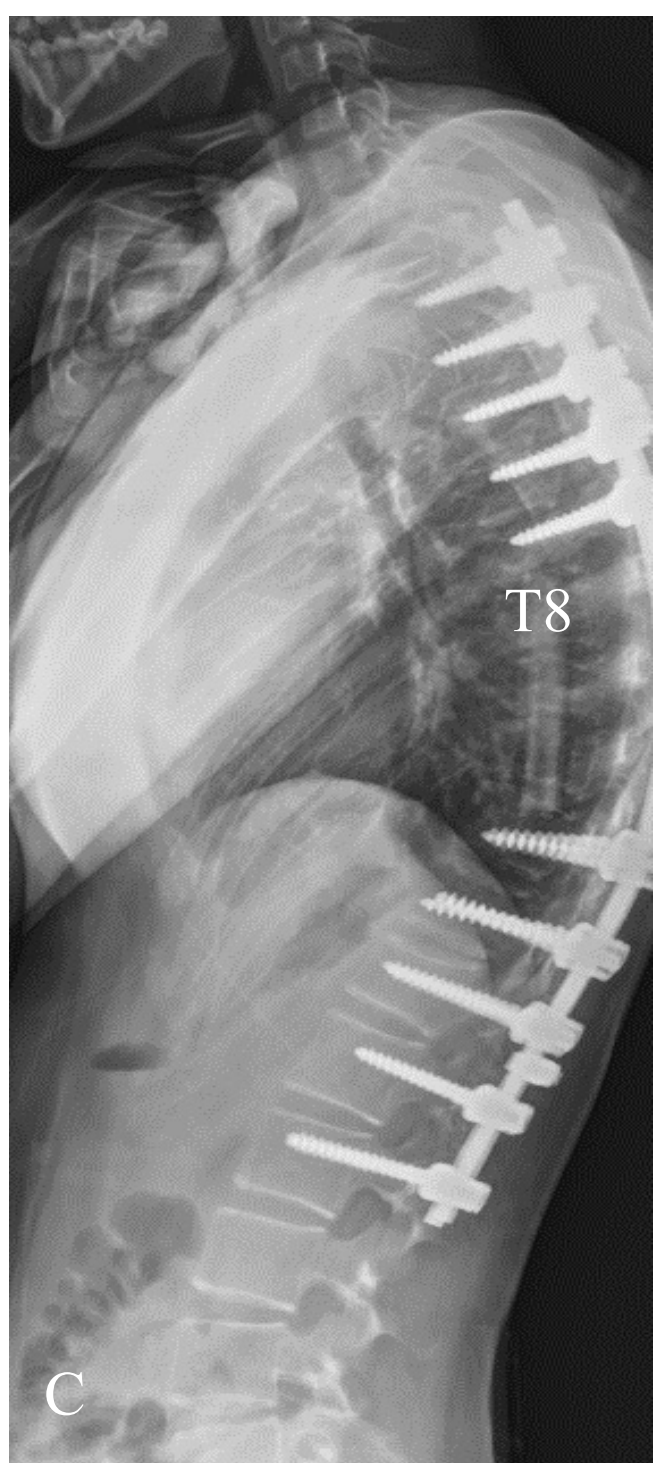




\begin{tabular}{|c|c|c|c|c|}
\hline Variable number (\%) & $\begin{array}{c}\text { Total } \\
(\mathrm{n}=31)\end{array}$ & $\begin{array}{c}\text { Postoperative } \\
\text { kyphosis }(\mathrm{n}=12)\end{array}$ & $\begin{array}{l}\text { No postoperative } \\
\text { kyphosis }(n=19)\end{array}$ & $P$-value $\dagger$ \\
\hline Number & 31 & $12(12 / 31 ; 39 \%)$ & $19(19 / 31 ; 61 \%)$ & \\
\hline Age at surgery (years) & $53.0 \pm 19.3$ & $49.6 \pm 22.4$ & $55.2 \pm 17.3$ & 0.442 \\
\hline Female N (\%) & $17(55 \%)$ & $9(9 / 12 ; 75 \%)$ & $8(8 / 19 ; 42 \%)$ & 0.072 \\
\hline Follow-up term (months) & $66.8 \pm 26.9$ & $78.8 \pm 31.9$ & $59.2 \pm 20.8$ & 0.077 \\
\hline \multicolumn{5}{|l|}{ Primary or reoperation } \\
\hline Primary & $26(26 / 31 ; 84 \%)$ & $10(10 / 26 ; 39 \%)$ & $18(16 / 26 ; 62 \%)$ & \multirow[t]{2}{*}{0.612} \\
\hline Reoperation & $5(5 / 31 ; 16 \%)$ & $2(2 / 5 ; 40 \%)$ & $3(3 / 5: 60 \%)$ & \\
\hline \multicolumn{5}{|l|}{ Level } \\
\hline Cervicothoracic & $1(1 / 31 ; 3 \%)$ & $0(0 / 1 ; 0 \%)$ & $1(1 / 1 ; 100 \%)$ & \multirow[t]{3}{*}{0.526} \\
\hline Thoracic & $20(20 / 31 ; 65 \%)$ & $9(9 / 20 ; 45 \%)$ & $11(11 / 20 ; 55 \%)$ & \\
\hline Thoracolumbar & $10(10 / 31 ; 32 \%)$ & $3(3 / 11 ; 27 \%)$ & $7(7 / 10 ; 70 \%)$ & \\
\hline \multicolumn{5}{|l|}{ Tumor localization } \\
\hline Intradural intramedullary & $13(13 / 31 ; 42 \%)$ & $4(4 / 13 ; 31 \%)$ & $9(9 / 13 ; 69 \%)$ & \multirow[t]{3}{*}{0.722} \\
\hline Intradural extramedullary & $13(13 / 31 ; 42 \%)$ & $6(6 / 13 ; 46 \%)$ & $9(7 / 13 ; 54 \%)$ & \\
\hline Extradural & $5(5 / 31 ; 16 \%)$ & $2(2 / 5 ; 40 \%)$ & $3(3 / 5 ; 60 \%)$ & \\
\hline \multicolumn{5}{|l|}{ Pathology } \\
\hline Schwannoma & $6(6 / 31 ; 19 \%)$ & $2(2 / 6 ; 33 \%)$ & $4(4 / 6 ; 67 \%)$ & \multirow[t]{2}{*}{0.109} \\
\hline Meningioma & $5(5 / 31 ; 19 \%)$ & $2(2 / 5 ; 40 \%)$ & $3(3 / 5 ; 60 \%)$ & \\
\hline
\end{tabular}


Spine Surgery and Related Research J-STAGE Advance Publication (August 23, 2021)

(C) The J apanese Society for Spine Surgery and Related Research. CC BY- NC- ND 4.0 (https://creativecommons.org/licenses/by- nc- nd/4.0/).

\begin{tabular}{|l|c|c|c|}
\hline Ependymoma & $5(5 / 31 ; 19 \%)$ & $4(4 / 5 ; 80 \%)$ & $1(1 / 5 ; 20 \%)$ \\
\hline Hemangioma & $5(5 / 31 ; 19 \%)$ & $0(0 / 5 ; 0 \%)$ & $5(5 / 5 ; 100 \%)$ \\
\hline Myxopapillary ependymoma & $2(2 / 31 ; 7 \%)$ & $2(2 / 2 ; 100 \%)$ & $0(0 / 2 ; 0 \%)$ \\
\hline Hemangioblastoma & $2(2 / 31 ; 7 \%)$ & $0(0 / 2: 0 \%)$ & $2(2 / 2 ; 100 \%)$ \\
\hline Anaplastic ependymoma & $1(1 / 31 ; 3 \%)$ & $0(0 / 0 ; 0 \%)$ & $1(1 / 1 ; 100 \%)$ \\
\hline Hemangiopericytoma & $1(1 / 31 ; 3 \%)$ & $0(0 / 0 ; 0 \%)$ & $1(1 / 1 ; 100 \%)$ \\
\hline Fibrous tumor & $1(1 / 31 ; 3 \%)$ & $0(0 / 0 ; 0 \%)$ & $1(1 / 1 ; 100 \%)$ \\
\hline Ewing tumor & $1(1 / 31 ; 3 \%)$ & $1(1 / 1 ; 100 \%)$ & $0(0 / 0 ; 0 \%)$ \\
\hline Intramedullary melanocytoma & $1(1 / 31 ; 3 \%)$ & $0(0 / 0 ; 0 \%)$ & $1(1 / 1 ; 100 \%)$ \\
\hline Unknown & $1(1 / 31 ; 3 \%)$ & $1(1 / 1 ; 100 \%)$ & $0(0 / 0 ; 0 \%)$ \\
\hline Mean values are presented as mean \pm SD. $\dagger$ Comparison between groups. & \\
\hline
\end{tabular}




\begin{tabular}{|c|c|c|c|c|}
\hline Variable & Total & $\begin{array}{c}\text { Postoperative } \\
\text { kyphosis }\end{array}$ & $\begin{array}{c}\text { No postoperative } \\
\text { kyphosis }\end{array}$ & $P$-value $\dagger$ \\
\hline \multicolumn{5}{|l|}{ Method } \\
\hline Laminectomy only & $16(16 / 31 ; 52 \%)$ & $8(8 / 16 ; 50 \%)$ & $8(8 / 16: 50 \%)$ & \multirow[t]{4}{*}{0.220} \\
\hline Laminoplasty only & $1(1 / 31 ; 3 \%)$ & $1(1 / 1 ; 100 \%)$ & $0(0 / 0 ; 0 \%)$ & \\
\hline Laminectomy and laminoplasty & $1(1 / 31 ; 3 \%)$ & $0(0 / 1 ; 0 \%)$ & $1(1 / 1 ; 100 \%)$ & \\
\hline $\begin{array}{l}\text { Laminectomy and/or laminoplasty combined w/ } \\
\text { fixation }\end{array}$ & $13(13 / 31 ; 42 \%)$ & $3(3 / 13 ; 23 \%)$ & $10(10 / 13 ; 77 \%)$ & \\
\hline Number of laminectomies (all patients) & $3.1 \pm 1.8$ & $3.9 \pm 2.2$ & $2.6 \pm 1.2$ & 0.046 \\
\hline Number of laminectomies (patients w/o fixation) & $3.4 \pm 2.0$ & $4.3 \pm 2.3$ & $2.4 \pm 0.7$ & 0.041 \\
\hline Number of laminoplasties & $0.3 \pm 1.0$ & $0.3 \pm 0.9$ & $0.3 \pm 1.1$ & 0.973 \\
\hline $\begin{array}{l}\text { Number of vertebrae that underwent laminectomy or } \\
\text { laminoplasty }\end{array}$ & $3.3 \pm 1.7$ & $4.0 \pm 1.9$ & $2.9 \pm 1.4$ & 0.070 \\
\hline \multicolumn{5}{|l|}{ Radiation therapy } \\
\hline Yes & $4(4 / 31 ; 13 \%)$ & $2(2 / 4 ; 50 \%)$ & $2(2 / 4 ; 50 \%)$ & \multirow[t]{2}{*}{0.507} \\
\hline No & $27(27 / 31 ; 87 \%)$ & $10(10 / 29 ; 37 \%)$ & $17(17 / 27 ; 63 \%)$ & \\
\hline
\end{tabular}




\begin{tabular}{|c|c|c|c|c|}
\hline Variable & $\begin{array}{c}\text { Total } \\
(\mathrm{n}=31)\end{array}$ & $\begin{array}{c}\text { Postoperative } \\
\text { kyphosis }(n=12)\end{array}$ & $\begin{array}{l}\text { No postoperative } \\
\text { kyphosis }(\mathrm{n}=19)\end{array}$ & $P$-value $\dagger$ \\
\hline UV-LV kyphotic angle at baseline $\left(^{\circ}\right)$ & $10.4 \pm 10.9$ & $14.3 \pm 15.5$ & $7.9 \pm 5.9$ & 0.116 \\
\hline UV-LV kyphotic angle at last follow-up $\left({ }^{\circ}\right)$ & $18.3 \pm 14.6$ & $29.5 \pm 17.0$ & $11.2 \pm 6.5$ & 0.003 \\
\hline$\Delta U V-L V$ kyphotic angle $\left({ }^{\circ}\right)$ & $7.9 \pm 7.5$ & $15.3 \pm 6.4$ & $3.3 \pm 3.2$ & $<0.001$ \\
\hline
\end{tabular}




\begin{tabular}{|l|l|l|}
\hline Table 4. Spearman correlation between demographic, or surgical parameters and $\Delta$ UV-LV kyphotic angle \\
\hline Parameter & Correlation coefficient & $P$-value \\
\hline Age at surgery & -0.066 & 0.725 \\
\hline Follow-up term (months) & 0.333 & 0.067 \\
\hline Number of laminectomies & $\mathbf{0 . 5 5 0}$ & $\mathbf{0 . 0 0 1}$ \\
\hline Number of laminoplasties & -0.096 & 0.606 \\
\hline Number of vertebrae that underwent laminectomy or laminoplasty & $\mathbf{0 . 4 5 3}$ & $\mathbf{0 . 0 1 1}$ \\
\hline UV-LV kyphotic angle at baseline & 0.332 & 0.068 \\
\hline UV-LV kyphotic angle at last follow-up & $\mathbf{0 . 6 9 5}$ & $\mathbf{0 . 0 0 0}$ \\
\hline Bold type indicates statistical significance. & & \\
\hline
\end{tabular}




\begin{tabular}{|c|c|c|c|}
\hline Variable & $\begin{array}{l}\text { With fixation } \\
\quad(\mathrm{n}=13)\end{array}$ & $\begin{array}{l}\text { Without fixation } \\
\quad(\mathrm{n}=18)\end{array}$ & $P$-value $\dagger$ \\
\hline Age at surgery (years) & $60.2 \pm 17.2$ & $47.8 \pm 19.4$ & 0.075 \\
\hline Female N (\%) & $7(7 / 13 ; 54 \%)$ & $10(10 / 18 ; 59 \%)$ & 0.925 \\
\hline Follow-up term (months) & $59.1 \pm 27.3$ & $72.3 \pm 26.0$ & 0.180 \\
\hline \multicolumn{4}{|l|}{ Primary or reoperation } \\
\hline Primary & $11(11 / 26 ; 42 \%)$ & $15(15 / 26 ; 58 \%)$ & \multirow[t]{2}{*}{0.659} \\
\hline Reoperation & $2(2 / 5 ; 40 \%)$ & $3(3 / 5 ; 60 \%)$ & \\
\hline \multicolumn{4}{|l|}{ Level } \\
\hline Cervicothoracic & $1(1 / 1 ; 100 \%)$ & $0(0 / 1 ; 0 \%)$ & \multirow[t]{3}{*}{0.398} \\
\hline Thoracic & $10(10 / 20 ; 50 \%)$ & $10(10 / 20 ; 50 \%)$ & \\
\hline Thoracolumbar & $3(3 / 10 ; 30 \%)$ & $7(7 / 10 ; 70 \%)$ & \\
\hline \multicolumn{4}{|l|}{ Tumor localization } \\
\hline Intradural intramedullary & $2(2 / 13 ; 15 \%)$ & $11(11 / 13 ; 85 \%)$ & \multirow[t]{3}{*}{0.024} \\
\hline Intradural extramedullary & $7(7 / 13 ; 54 \%)$ & $6(6 / 13 ; 46 \%)$ & \\
\hline Extradural & $4(4 / 5 ; 80 \%)$ & $1(1 / 5 ; 20 \%)$ & \\
\hline \multicolumn{4}{|l|}{ Pathology } \\
\hline Schwannoma & $3(3 / 6 ; 50 \%)$ & $3(3 / 6 ; 50 \%)$ & \multirow[t]{4}{*}{0.119} \\
\hline Meningioma & $4(4 / 5 ; 80 \%)$ & $1(1 / 5 ; 20 \%)$ & \\
\hline Ependymoma & $0(0 / 5 ; 0 \%)$ & $5(5 / 5 ; 100 \%)$ & \\
\hline Hemangioma & $2(2 / 5 ; 40 \%)$ & $3(3 / 5 ; 60 \%)$ & \\
\hline
\end{tabular}




\begin{tabular}{|c|c|c|c|}
\hline Myxopapillary ependymoma & $0(0 / 2 ; 0 \%)$ & $2(2 / 2 ; 100 \%)$ & \\
\hline Hemangioblastoma & $2(2 / 2: 100 \%)$ & $0(0 / 2 ; 100 \%)$ & \\
\hline Anaplastic ependymoma & $0(0 / 0 ; 0 \%)$ & $1(1 / 1 ; 100 \%)$ & \\
\hline Hemangiopericytoma & $1(1 / 1 ; 100 \%)$ & $0(0 / 1 ; 0 \%)$ & \\
\hline Fibrous tumor & $0(0 / 0 ; 0 \%)$ & $1(1 / 1 ; 100 \%)$ & \\
\hline Ewing tumor & $0(0 / 1 ; 100 \%)$ & $1(1 / 1 ; 100 \%)$ & \\
\hline Intramedullary melanocytoma & $0(0 / 0 ; 0 \%)$ & $1(1 / 1 ; 100 \%)$ & \\
\hline Unknown & $1(1 / 1 ; 100 \%)$ & $0(0 / 0 ; 0 \%)$ & \\
\hline Number of laminectomies & $2.8 \pm 1.4$ & $3.4 \pm 2.0$ & 0.343 \\
\hline Number of laminoplasties & $0.0 \pm 0.0$ & $0.4 \pm 1.3$ & 0.177 \\
\hline $\begin{array}{l}\text { Number of vertebrae that underwent } \\
\text { laminectomy or laminoplasty }\end{array}$ & $2.8 \pm 1.4$ & $3.7 \pm 1.8$ & 0.116 \\
\hline \multicolumn{4}{|l|}{ Radiation therapy } \\
\hline Yes & $1(1 / 4 ; 25 \%)$ & $3(3 / 4 ; 75 \%)$ & \multirow[t]{2}{*}{0.434} \\
\hline No & $12(12 / 27 ; 44 \%)$ & $15(15 / 27 ; 56 \%)$ & \\
\hline UV-LV kyphotic angle at baseline $\left({ }^{\circ}\right)$ & $8.8 \pm 5.4$ & $11.5 \pm 13.6$ & 0.501 \\
\hline UV-LV kyphotic angle at last follow-up $\left({ }^{\circ}\right)$ & $14.5 \pm 6.7$ & $21.0 \pm 18.1$ & 0.173 \\
\hline$\Delta$ UV-LV kyphotic angle $\left(^{\circ}\right)$ & $5.7 \pm 3.9$ & $9.5 \pm 9.0$ & 0.125 \\
\hline
\end{tabular}

Mean values are presented as mean \pm SD. $†$ Comparison between groups. Bold type indicates statistical significance. 